( 2017 , THE AUTHORS. Published by FASS and Elsevier Inc. on behalf of the American Dairy Science Association ${ }^{\circledR}$.

This is an open access article under the CC BY-NC-ND license (http://creativecommons.org/licenses/by-nc-nd/3.0/).

\title{
Herd-level prevalence of selected endemic infectious diseases of dairy cows in Great Britain
}

\author{
Martina Velasova, ${ }^{* 1}$ Angela Damaso, ${ }^{*}$ Bhagyalakshmi Chengat Prakashbabu, ${ }^{*}$ Jenny Gibbons, $\dagger$ \\ Nick Wheelhouse,‡ David Longbottom, $\ddagger$ Steven Van Winden, ${ }^{*}$ Martin Green,§ and Javier Guitian* \\ *Veterinary Epidemiology, Economics and Public Health Group, Department of Pathobiology and Population Science, Royal Veterinary College, \\ Hawkshead Lane, North Mymms, Hertfordshire, AL9 7TA United Kingdom \\ †AHDB Dairy, Agriculture and Horticulture Development Board, Stoneleigh Park, Kenilworth, Warwickshire, CV8 2TL United Kingdom \\ ¥Moredun Research Institute, Pentlands Science Park, Bush Loan, Penicuik, Midlothian EH26 OPZ, United Kingdom \\ $\S$ The School of Veterinary Medicine and Science, University of Nottingham, Sutton Bonington Campus, Sutton Bonington, Leicestershire, \\ LE12 5RD United Kingdom
}

\section{ABSTRACT}

To implement appropriate and effective disease control programs at the national level, up-to-date and unbiased information on disease frequency is needed. The aim of this study was to estimate the prevalence of selected endemic infectious diseases in the population of dairy herds in Great Britain. Bulk milk tank (BMT) samples from 225 randomly selected dairy farms, stratified by region and herd size, were tested for antibodies against bovine viral diarrhea virus (BVDV), bovine herpesvirus type 1, Mycobacterium avium ssp. paratuberculosis, Leptospira Hardjo, Salmonella spp., Coxiella burnetii, Fasciola hepatica, Neospora caninum, and Ostertagia ostertagi. Furthermore, the presence of BVDV, C. burnetii, and Chlamydia-like organisms was determined by PCR. The apparent herd prevalence was estimated as a weighted proportion of positive herds. The true prevalence was calculated when a test was used with known test characteristics for the cut-off value used. Among unvaccinated herds, the true prevalence of BMT antibodies against BVDV was estimated at $66 \%$ [95\% confidence interval (CI): 56-77\%], M. avium ssp. paratuberculosis $68 \%$ (95\% CI: 59-77\%), bovine herpesvirus type $162 \%$ (95\% CI: 52-73\%), Leptospira Hardjo 47\% (95\% CI: 34-60\%), and Salmonella spp. $48 \%$ (95\% CI: 39-56\%). The apparent prevalence of BMT antibodies against C. burnetii was 80\% (95\% CI: 75-85\%), F. hepatica $55 \%$ (95\% CI: 48-62\%), N. caninum $46 \%$ (95\% CI: 38-54\%), and O. ostertagi 95\% (95\% CI: 91-98\%). The BVDV, C. burnetii, and Chlamydia-like antigens were detected in 5 (95\% CI: 2-9\%), 29 (95\% CI: $21-36 \%$ ), and $31 \%$ (95\% CI: $24-38 \%$ ) of herds, respectively. Our results show that dairy cows across GB are frequently exposed to the studied pathogens, which

Received August 11, 2016.

Accepted May 14, 2017.

${ }^{1}$ Corresponding author: mvelasova@rvc.ac.uk are endemic at high levels with some geographical variations. These prevalence estimates provide a muchneeded basis to assess whether nationwide control programs for the studied pathogens are justified by their potential economic, environmental, and public health implications. Should surveillance and control programs be initiated, the estimates presented here are a baseline against which progress can be assessed.

Key words: prevalence, endemic infectious disease, dairy cow, bulk milk, ELISA

\section{INTRODUCTION}

Several infectious diseases of dairy cows such as bovine viral diarrhea virus (BVDV), Johne's disease caused by Mycobacterium avium ssp. paratuberculosis (MAP), infectious bovine rhinotracheitis, and liver fluke are generally regarded as being widespread and endemic in the United Kingdom (Carslake et al., 2011; Sekiya et al., 2013). These diseases are known to have a significant effect on dairy production due to their effects on fertility (Fray et al., 2000; Lanyon et al., 2014; Walz et al., 2015), milk production (Tiwari et al., 2007; McAloon et al., 2016), and, subsequently, culling (Murphy et al., 2006; Smith et al., 2010).

In Great Britain (GB) in 2005, the total costs of dairy and beef cattle endemic infectious diseases (disease, control, and prevention) were estimated to be as high as $£ 10$ million (\$12.4 million) for Johne's disease and $£ 61.1$ million ( $\$ 75.7$ million) per annum for BVDV (Bennett and Ijpelaar, 2005). However, due to a lack of reliable prevalence data at national level, these figures are likely to underestimate the true situation. With the exception of bovine tuberculosis in GB and BVDV in Scotland, controlling such diseases is voluntary for GB farmers. However, the need to control endemic infectious disease can be overlooked by farmers, as it can be difficult to associate their presence with visible losses. This is often because clinical signs associated with 
such diseases on a given animal in an infected herd are absent, mild, or nonspecific, leading to a general acceptance of their occurrence on dairy farms in endemic areas (Carslake et al., 2011; Statham, 2011). In such cases, from the farmers' perspective, there is often very little, if any, financial incentive to control the disease (Stott et al., 2005). Nevertheless, examples from European countries suggest that the control or elimination of some of these pathogens [e.g., bovine herpesvirus type 1 (BHV-1) in Scandinavian countries and Austria, BVDV in Sweden] can be achieved and would be beneficial (Ackermann and Engels, 2006; Lindberg et al., 2006).

When control programs are implemented, it is important that they are accompanied by continuous monitoring of herd status to assess the effectiveness of the program and progress toward goals; this can be achieved through serological testing at the herd level (Lindberg and Alenius, 1999; Houe et al., 2006). Testing of bulk milk samples is a particularly cost-effective strategy and has become part of surveillance and disease-control programs for several endemic infectious diseases of dairy cattle (Booth et al., 2013; Sekiya et al., 2013).

The application of a suitable disease control or elimination program at national or regional level and the monitoring of the progress of that program should be based on knowledge of the baseline frequency and distribution of the disease in the population (Ackermann and Engels, 2006; Humphry et al., 2012; Sayers et al., 2015). Such estimates can allow informed decisions on the justification of a program at the national level and provide a baseline against which the effect of the control program can be assessed. With the exception of BVDV in Scotland, for which a survey of Scottish dairy farms has recently been carried out to inform the Scottish BVDV elimination program (Humphry et al., 2012), presently, in GB, there is a lack of reliable and up-to-date estimates of the prevalence of endemic diseases in the national dairy herd. This is because, for the majority of endemic diseases, no active disease surveillance is in place. Several private and public routine recording systems exist; however, at the national level, the information they provide is likely to be biased (Velasova et al., 2015).

In addition to these ongoing recording systems, oneoff surveys are often carried out (Davison et al., 2005; Salimi-Bejestani et al., 2005; Woodbine et al., 2009b); although useful, their results should be interpreted with caution because of issues such as nonprobabilistic selection of studied farms (Paton et al., 1998; Woodbine et al., 2009b; Williams and Winden, 2014) and failure to adjust prevalence estimates for the study design (Paton et al., 1998) or for test performance (Davison et al., 2005; Woodbine et al., 2009a; Williams and Winden,
2014). Furthermore, one-off studies are only useful for a limited period of time, as the prevalence can change as a result of the implementation of control measures and changes in the dairy industry, the more apparent of which are increased herd size, genetic selection, and application of new technological innovations (Barkema et al., 2015). It is therefore reasonable to assume that the few available estimated prevalence figures could no longer be accurate. Accordingly, the aim of our study was to generate new information on the prevalence and distribution of selected important infectious diseases of dairy cows at the national level to provide a basis for a future monitoring of disease trends over time and for the implementation of suitable and effective disease control or elimination programs at the national level.

\section{MATERIALS AND METHODS}

\section{Study Population and Sampling Design}

A nationwide, cross-sectional study of commercial dairy herds was conducted in GB from April 2014 to March 2015. The study population was selected by means of stratified random sampling from a sample frame comprising 10,491 dairy farms, representing approximately $95 \%$ of the total population of all dairy farms in GB, held by the dairy industry (AHDB Dairy, division of the Agricultural and Horticultural Development Board). The registered farms were stratified by 6 regions (north England, Midlands, southeast England, southwest England, Scotland, and Wales) and then within each region by herd size (small: $<50$ cows; medium: 50-149 cows; large: $\geq 150$ cows), creating 18 strata. The herd size was based on the total number of lactating and dry cows. An equal number of farms within each stratum was selected using simple random sampling. The total number $(n)$ of farms to study was calculated using ProMesa software v.1.62 (http://www .promesa.co.nz/) according to the formula:

$$
\begin{gathered}
n=\frac{\sum_{i=1}^{e}\left[\frac{\left(n_{i}\right)^{2} \times p_{i} \times\left(1-p_{i}\right)}{w_{i}}\right]}{N^{2} \times \frac{A E^{2}}{Z^{2}}+\sum_{i=1}^{e}\left[n_{i} \times p_{i} \times\left(1-p_{e}\right)\right]}, \\
w_{i}=\frac{n_{i} \times \sqrt{p_{i} \times\left(1-p_{i}\right)}}{\sum_{i=1}^{e}\left[n_{i} \times \sqrt{p_{i} \times\left(1-p_{i}\right)}\right]},
\end{gathered}
$$

where $e$ is the number of strata, $n_{i}$ is the number of farms in stratum $i$ (i.e., large farms in Scotland), $p_{i}$ is the expected prevalence in stratum $i$ (50\% was used as 
worst-case scenario), $N$ is the total number of farms in the population $(10,491), A E$ is absolute acceptable error (error of $14 \%$ to achieve $7 \%$ precision for the assumed $50 \%$ prevalence), 1.96 is the critical $Z$ score value for a $95 \%$ confidence interval, and $w_{i}$ is a weighting factor of each stratum. For purpose of sample size calculation, perfect sensitivity and specificity of the diagnostic tests were assumed. A total sample of 200 farms was found to be sufficient to generate the desired estimates, and it was decided to aim to recruit 250 farms (approximately 40 farms from each region with approximately equal number of farms within each herd size category).

Based on previous experiences of the dairy industry, it was expected that around $20 \%$ of farmers contacted would be willing to participate in the study. The selected farmers were contacted by post, receiving information about the project and their participation. Farmers not responding to the initial letter received a reminder. Cattle veterinary practitioners were also informed about the project through the British Cattle Veterinary Association newsletter and by email and were also asked to encourage their clients to participate if they received a letter inviting them. Farmers who agreed to participate were included in the study and the status of their farms with respect to 10 different pathogens was assessed. Selection of specific pathogens was based on the results of a workshop run by the Royal Veterinary College in April 2012. In the workshop, the participants were asked to identify and rank cattle health conditions considered important for individual farmers and the dairy industry for which no reliable and up-to-date nationwide estimates were available (Velasova et al., 2015). Additionally, 5 more pathogens for which no upto-date nationwide estimates were identified that could be detected using bulk milk samples and were included.

\section{Ascertainment of Disease Status}

Farm-level status with regard to BVDV, MAP, BHV1, Salmonella spp., Leptospira Hardjo, Coxiella burnetii, Fasciola hepatica, Neospora caninum, and Ostertagia ostertagi was assessed by testing a single or repeated bulk milk tank (BMT) samples for the presence of specific antibodies (Table 1). In addition, for 3 of the pathogens (BVDV, C. burnetii, and Chlamydia-like organisms), direct detection of the antigen in bulk milk was carried out.

From each farm, a BMT sample of approximately 30 $\mathrm{mL}$ was collected and kept refrigerated until arrival at the laboratory. On arrival, fresh milk samples were put into refrigerated storage set at a temperature between 1 and $7^{\circ} \mathrm{C}$. To each sample, $5 \mathrm{~mL}$ of Bronopol (Wychem Ltd., Newmarket, UK) preservative was added. Commercially available ELISA, described in Table 1, were

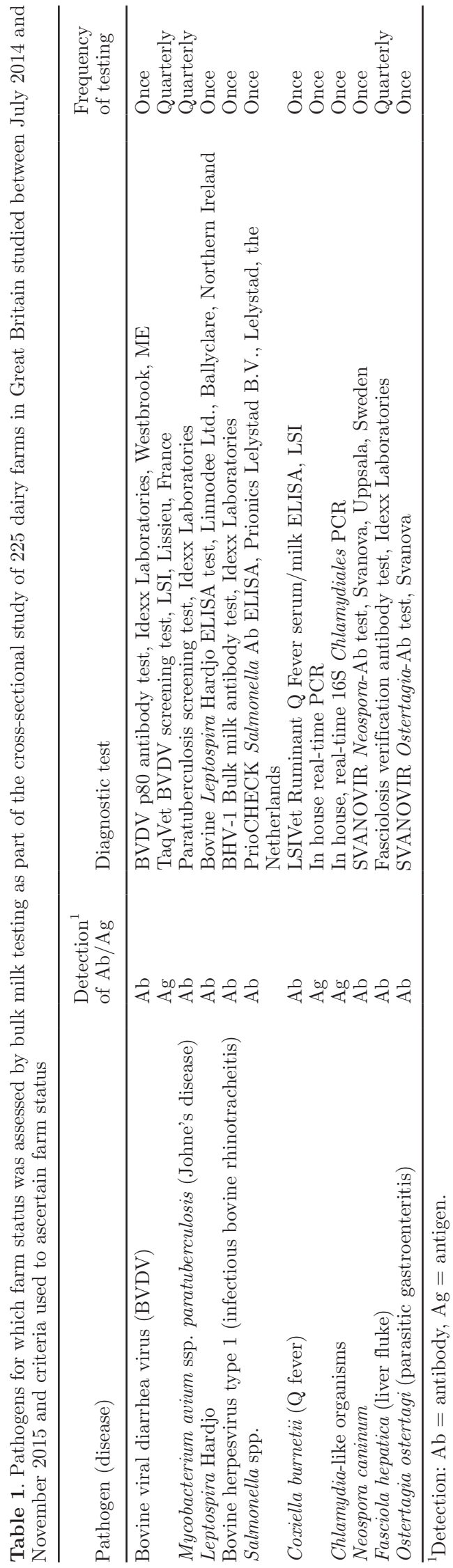

Journal of Dairy Science Vol. 100 No. 11, 2017 
performed according to the manufacturers' instructions. If an option for short and long incubation was available, the long incubation was used. The results were calculated according to the manufacturer's instructions as (1) a sample-to-positive percentage calculated as the ratio of the optical density of the sample $\left(\mathrm{OD}_{\mathrm{S}}\right)$ minus the optical density of the negative control $\left(\mathrm{OD}_{\mathrm{NC}}\right)$ to the optical density of the positive control $\left(\mathrm{OD}_{\mathrm{PC}}\right)$ minus optical density of the negative control $\left(\mathrm{OD}_{\mathrm{NC}}\right) \times 100$, or as (2) the percentage inhibition, calculated as $(1-$ $\left.\mathrm{OD}_{\mathrm{S}} / \mathrm{OD}_{\mathrm{NC}}\right) \times 100$. One exception to the interpretation of the results was made; a positive cut-off value of 12.5 instead of $30 \% \mathrm{~S} / \mathrm{P}$ was used to identify MAP-positive herds, as described by van Weering et al. (2007).

The presence of BVDV antigen was studied by means of a real-time PCR protocol (TaqVet BVDV screening test, LSI, Lissieu, France). The presence of C. burnetii antigen was assessed by means of an in-house real-time PCR protocol developed by Klee et al. (2006). An inhouse real-time PCR (16S Chlamydiales PCR) according to Lienard et al. (2011) was also used to detect Chlamydia-like organisms.

All the analyses were carried out on a single BMT sample with the exception of the detection of antibodies against MAP and F. hepatica and the detection of BVDV antigen, which were carried out on 4 samples collected at an interval of once every 3 mo. This was carried out to increase the detection of positive farms considering the low sensitivity of bulk milk ELISA tests for the detection of MAP (van Weering et al., 2007) and F. hepatica (Reichel et al., 2005) and higher prevalence of BVDV among young stock (Booth et al., 2013).

\section{Data Collection}

A standardized questionnaire was used to gather information on general farm characteristics (i.e., herd size, production type), vaccination status, the main herd health problems as perceived by the farmer at the time of the visit, and the farmer's knowledge of the disease status of the farm for each disease in question. With respect to the farmer's perception of their farm's disease status, the farms were divided into 5 categories: (1) disease definitely present (based on previous laboratory testing or abattoir monitoring); (2) disease present but unsure (no previous laboratory testing was carried out); (3) disease definitely not present (previous laboratory testing was carried out); (4) disease not present but unsure; and (5) unknown disease status. The questionnaire was designed in consultation with 2 veterinary practitioners and was piloted on 4 farms before use. Questions that appeared to be unclear to farmers were rephrased to improve the clarity. Interviews were carried out by 7 interviewers (3 qualified veterinarians and 4 final-year veterinary students), all of whom were trained to ensure consistency of the collected data.

\section{Data Analysis}

All questionnaire data and the results of the laboratory testing were entered into a Microsoft Access 2007 (Microsoft Corp., Redmond, WA) database. The accuracy of information in the database was crosschecked with the questionnaire. All categorical variables were summarized using frequencies and percentages. All continuous variables were checked for deviations from the normal distribution using histograms and the normality test for skewness and kurtosis. They were summarized using frequencies and medians with ranges (minimum and maximum). The descriptive statistics were calculated using Stata 11.2 (StataCorp, College Station, TX) software.

Prevalence Estimation-Single Disease Testing. For the estimation of prevalence at the herd level, the results of assays were dichotomized as positive or negative based on the cut-offs summarized, which is presented in Table 2. The apparent herd prevalence $(p)$ of individual pathogens at the national level was calculated as the total number of positive herds divided by the total number of herds sampled, weighted to account for the stratified study design. Sampling weights were calculated using the AHDB Dairy sampling frame described above (where the dairy cattle population was stratified by 6 regions and within each region further by 3 herd size categories). For each stratum $i$ (i.e., small farms in Wales) the sampling weight was calculated as $1 /$ probability of a farm being selected. The probability of a farm being selected in stratum $i$ was calculated as several farms studied from stratum $i$ divided by the number of registered farms in that stratum. The weighted population prevalence $(p)$ and $95 \%$ confidence intervals were calculated using survey package in Stata 11.2 according to formulae described in Stata manual (StataCorp, 2013). The 95\% confidence intervals were adjusted by estimating the standard error using linearization method with a first-order Taylor approximation of the point estimates (StataCorp, 2013).

The true herd prevalence was calculated for those conditions considered biologically meaningful to dichotomies herds as not infected or infected and for which reliable information on the diagnostic test characteristic for the cut-off were available. The latter information included (1) herd-level sensitivity (Se) and specificity (Sp) of the diagnostic tests used and (2) a cut-off value (as per test manufacturer instruction) to classify herds as positive or negative above or below this threshold. The point estimates and confidence intervals were 
PREVALENCE OF ENDEMIC DISEASES

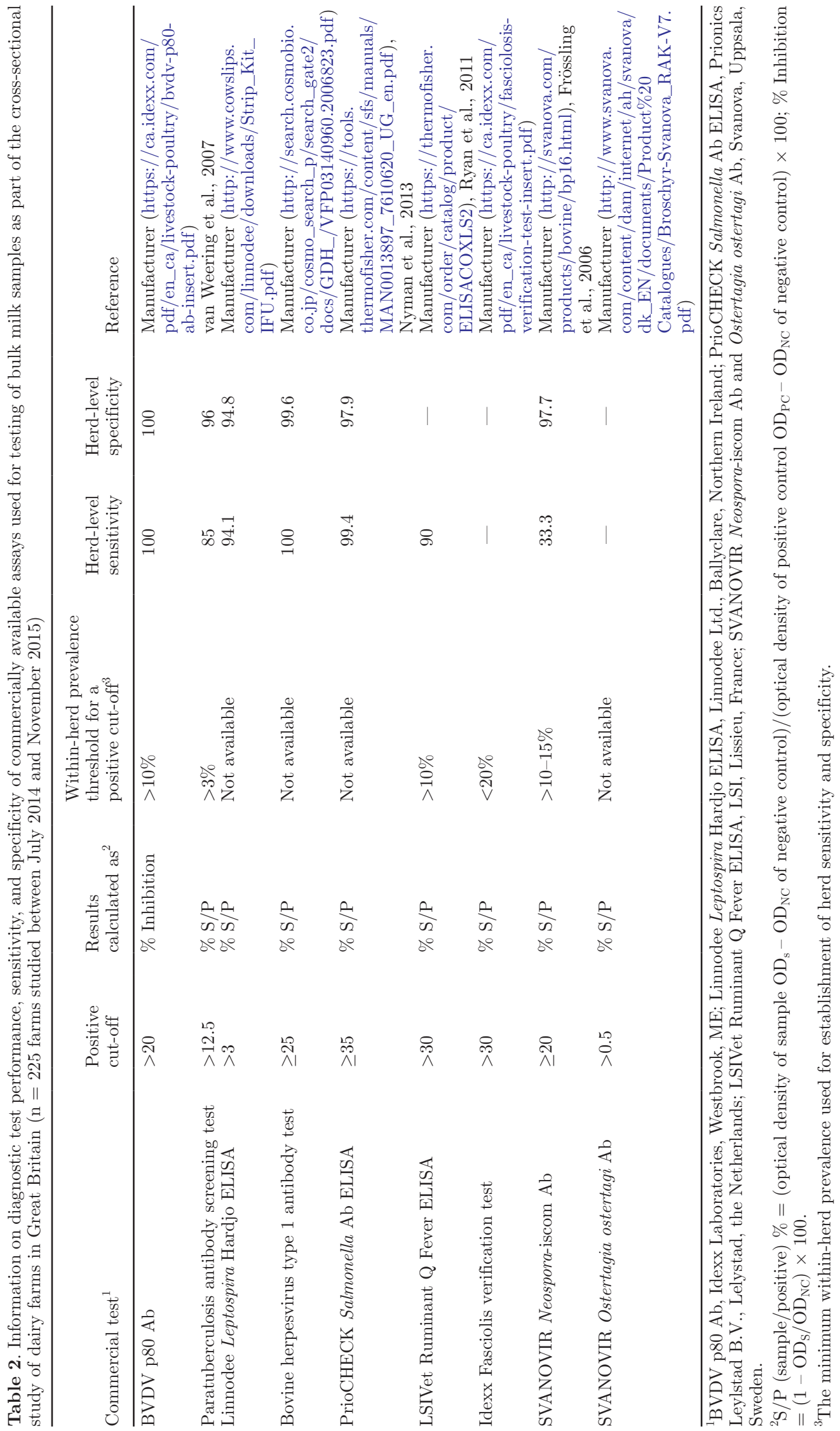


adjusted for the Se and Sp of the diagnostic tests as described by Rogan and Gladen (1978). Information on herd-level Se and Sp of the diagnostic tests, as well as the minimum proportion of positive animals for the establishment of herd Se and Sp, was obtained either directly from the manufacturers or through available literature and is summarized in Table 2. In the case of the prevalence of $O$. ostertagi, F. hepatica, N. caninum, and $C$. burnetii, only apparent prevalence is presented, as no reliable information on the respective diagnostic tests Se and Sp were obtained. All PCR tests were assumed to have $100 \%$ Se and Sp. Because of the inability of the antibody assays that were performed to distinguish between vaccinated and unvaccinated herds, vaccinated herds and herds for which vaccination status was unavailable were removed from the analysis.

Correlations between studied pathogens in unvaccinated herds were assessed by Phi correlation coefficient $(\phi)$, calculated as the square root of chi-squared divided by $\mathrm{n}$, the total number of observations (Olivier and Bell, 2013). A chi-squared test was performed to assess the association of herd status (positive/negative) with region or herd size. Variations in the prevalence, taking into account the effect of both region and herd size (independent variables), were assessed using logistic regression, and strength of the associations was measured by calculating adjusted odds ratios and their confidence intervals (CI). Statistical significance of the associations of both independent variables with the herd status was tested using a Wald test with $\alpha=5 \%$.

Repeated Quarterly Testing. The apparent and true herd prevalence of antibodies against MAP and $F$. hepatica and the presence of BVDV at each quarterly test were estimated as described above. Only farms that completed all 4 quarterly tests were included in the analysis. To estimate overall period prevalence, a herd was considered positive if at least 1 of the samples tested positive in a given quarterly test during a 12mo period. The true period herd prevalence was then calculated based on a combined Se and $\mathrm{Sp}$ of the tests in parallel as $\mathrm{Se}_{\text {combined }}=\mathrm{Se} \times \mathrm{n}-(\mathrm{Se})^{\mathrm{n}}$ and $\mathrm{Sp}_{\text {combined }}$ $=\mathrm{Sp}^{\mathrm{n}}$, where $\mathrm{n}=$ number of tests carried out. The $\mathrm{Se}_{\text {combined }}$ and $\mathrm{Sp}_{\text {combined }}$ of MAP ELISA test in parallel were calculated as 1.0 and 0.85 , respectively. For the BVDV PCR test, $\mathrm{Se}_{\text {combined }}$ and $\mathrm{Sp}_{\text {combined }}$ of 1 were used.

Farmers' Perception. Positive and negative predictive values were calculated as the proportion of farms where farmers correctly classified the status of the herd with respect to the pathogens under study using the results of the BMT as the gold standard. Herds vaccinated against the studied pathogens or those were farmers did not know the status of the tested pathogens were excluded from the calculations.

\section{Spatial Analysis}

Choropleth maps showing the distribution of positive herds across the studied regions were generated by dividing the number of positive herds by the number of herds tested within each region (where possible adjusted for the performance of the diagnostic tests used), using ArcGIS 10 (ESRI Inc., Redlands, CA) software. Presence of spatial autocorrelation was tested using the univariate Moran's I test for global spatial autocorrelation and Queen contiguity (i.e., considering as neighboring units those that have any point such as boundaries or corners in common). To account for the variation in number of farms tested and the underlying population structure, the prevalence estimates were adjusted toward the overall average by applying the empirical Bayes smoothing (Anselin, 2004; Anselin et al., 2004). Statistical significance of the Moran's I was tested using Monte Carlo randomization with 9,999 permutations. The analyses of global spatial autocorrelation were carried out using the GeoDa 1.6.7 software (https://geodacenter.asu.edu).

Areas with significantly higher or lower proportion of BMT-positive herds (clusters) were identified using a spatial scanning method, the scan statistic. The testing was performed using Bernoulli probability model in SatScan version 9.4.2 (www.satscan.org; Kulldorff, 1997). The maximum cluster size tested was $50 \%$ of the population at risk. The geographic information was based on the farm postcode (easting and northing coordinates) corresponding to the farm address registered within the AHDB Dairy database collected as part of the recruitment process. Identified clusters were considered significant at $P<0.05$, based on Monte Carlo hypothesis testing with 9,999 permutations.

The project was approved by the Ethics and Welfare committee at the Royal Veterinary College (approval number URN 2013 0097H).

\section{RESULTS}

\section{Farm Recruitment}

Of the 1,483 selected dairy farms, 553 farms responded (37\% response rate), with 279 negative and 274 positive answers. Of the 274 farms that agreed to participate, 225 farms were studied (had milk sample tested for some or all of the diseases and completed the questionnaire), representing approximately $2 \%$ of the total population of dairy farms in GB. The remaining 49 farms that initially answered positively either went out of milk production, were no longer contactable, or were no longer interested in the study for various reasons. 


\section{Farm Characteristics}

The median herd size was 133 adult cows and ranged from 14 to 603. Approximately half $(117 / 225)$ of the farms were mixed dairy farms (dairy farms with other production animals; i.e., beef or sheep), and the majority of the farms $(93 \%, 209 / 225)$ were conventional (as opposed to organic) dairy producers. One hundred sixty-four farms $(73 \%)$ managed their milking herd as 1 production group, and the remaining farms had 2 or more groups of high- and low-yielding cows. The average milk yield per cow per year in 2013 was 7,613 $\mathrm{L}($ median $=7,822$, range $=3,100-11,679 \mathrm{~L})$. Information on calving intervals was recorded from 205 farms with median of $406 \mathrm{~d}$ ( range $=310-474 \mathrm{~d}$ ). On the majority of farms cows calved year round $(74 \%$, $165 / 224)$. The most common grazing system was grazing in summer and housed in winter $(89 \%, 200 / 225)$. On $13(6 \%)$ farms, cows were kept indoor year round; on the remaining farms, cows were kept outdoor year round. Cubicles (i.e., freestalls) were the most common (79\%, 164/208) type of housing for milking cows, with $27(13 \%)$ farms housing milking cows in straw yards and the remaining farms using both type of housing. One hundred seven farms (48\%) purchased new cattle during a $12 \mathrm{mo}$ period before the farm visit.

\section{Point Prevalence}

Initial BMT samples were obtained for all farms between July 2014 and March 2015, with 144 farms (64\%) tested between July and September 2014. The estimated herd prevalence of the studied pathogens based on the presence of antibodies (on unvaccinated farms) or antigen (all farms) in the initial BMT samples was high, with a higher proportion of positive herds found among medium (50-150 cows) and large ( $\geq 150$ cows) herds (Table 3). The true prevalence of antibodypositive unvaccinated herds ranged from 48 (95\% CI: 40-56) to 68\% (95\% CI: 61-76) for Salmonella spp. and MAP, respectively. Of the $9 \mathrm{BVDV}$ antigen-positive herds, 7 vaccinated against BVDV. Among BVDV unvaccinated herds, 2 herds were both BVDV antigenand antibody-positive. Of the $57 \mathrm{C}$. burnetii antigenpositive herds, 55 herds had also antibodies detected. The distribution of ELISA antibody levels, expressed as percent positivity or percent inhibition (BVDV), is presented in Figure 1. Of the pathogens tested, among unvaccinated herds, a correlation of positive status was found between (1) BVDV antibody and BHV-1, Leptospira Hardjo, and F. hepatica; (2) BHV-1 and MAP and Leptospira Hardjo; and (3) C. burnetii antibody- and antigen-positive herds (Table 4). Correlation between BVDV antibody and antigen positivity was very low.

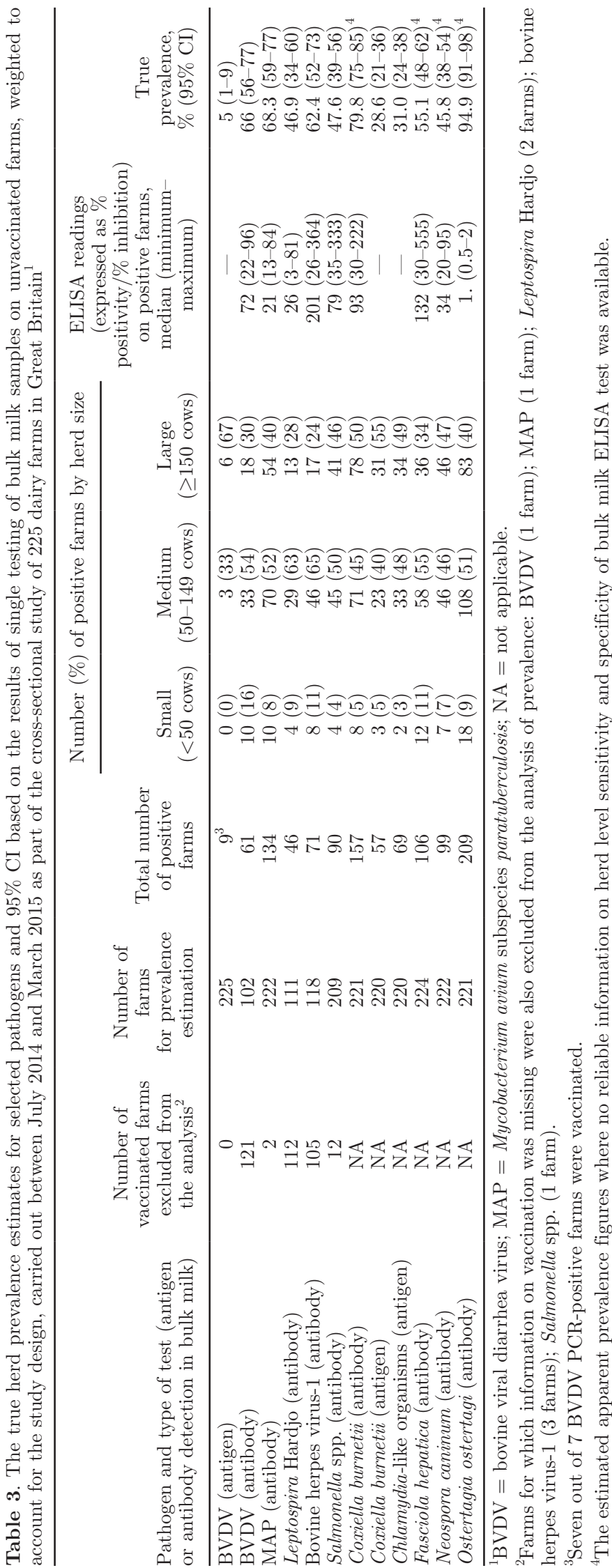

Journal of Dairy Science Vol. 100 No. 11, 2017 


\section{Associations of Prevalence with Region and Herd Size}

In the univariable analysis, herd-level prevalence differed among regions for BVDV antibody $(P=$ 0.01), BVDV antigen $(P=0.03)$, Leptospira Hardjo $(P<0.001)$, MAP $(P=0.04)$, Salmonella spp. $(P=$
0.001), C. burnetii antibody $(P=0.01)$, Chlamydia-like organisms $(P=0.04)$, and $F$. hepatica $(P<0.001)$. Differences in herd-level prevalence by herd size were also observed for $C$. burnetii antibody $(P<0.001), F$. hepatica $(P=0.02)$, and $O$. ostertagi $(P=0.05)$.

Accounting for the effect of herd size, regional variations in herd-level prevalence remained apparent for
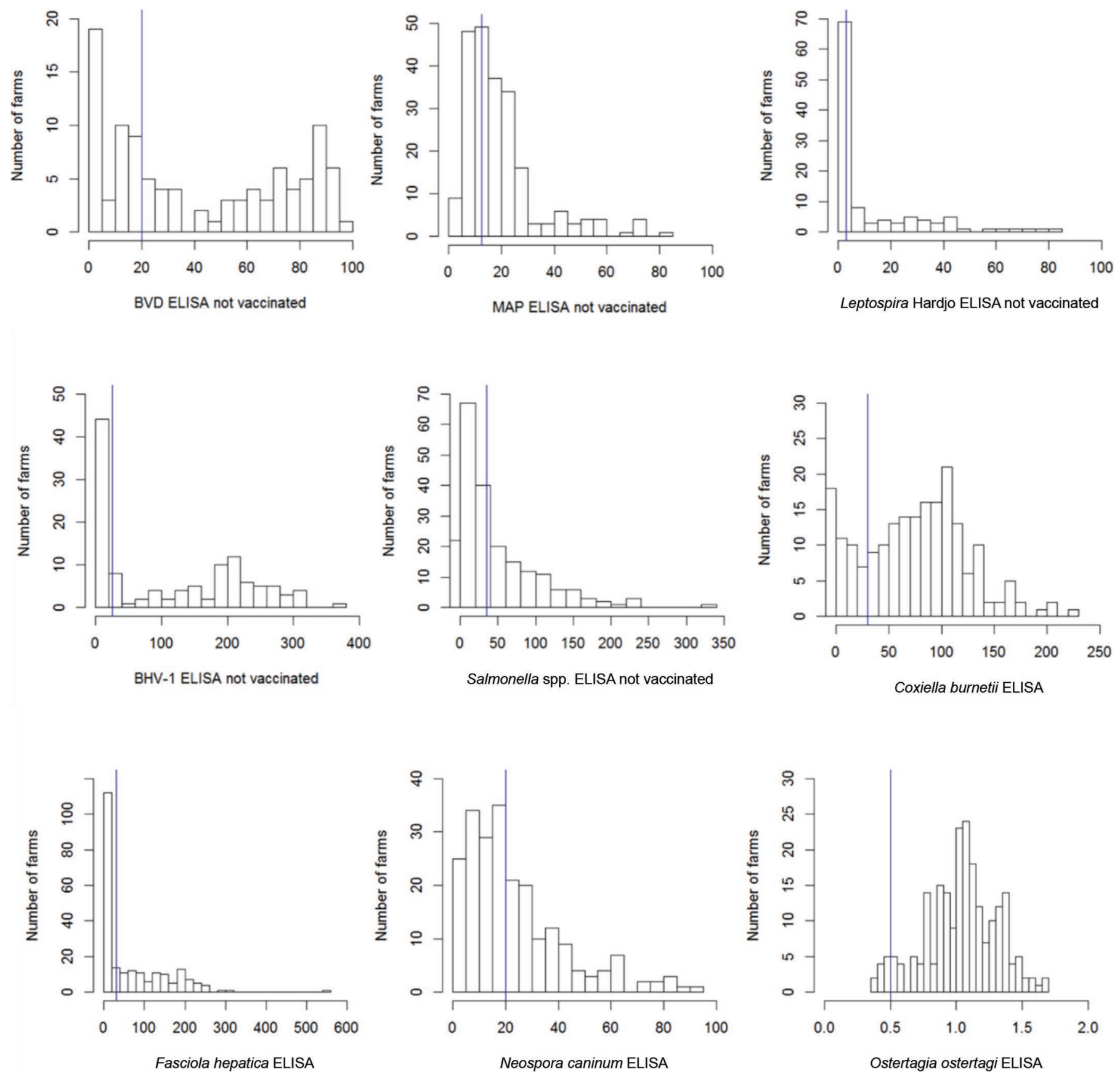

Figure 1. Results of antibody titers on unvaccinated farms detected by serological testing of bulk milk samples between July 2014 and March 2015, interpreted as a percent positivity or percent inhibition (for bovine viral diarrhea virus). The blue vertical line indicates cut-offs for negative or positive ELISA results. BVD = bovine viral diarrhea virus; $\mathrm{MAP}=$ Mycobacterium avium ssp. paratuberculosis; $\mathrm{BHV}-1=$ bovine herpes virus 1. Color version available online. 
most of the studied pathogens (Table 5). Herds located in Wales and Scotland had higher odds of being positive to BVDV antibody, BHV-1, Leptospira Hardjo, Salmonella spp., and F. hepatica. Herds located in southwest England had the highest odds of being positive for MAP and $C$. burnetii compared with the herds in southeast England. Accounting for the effect of region, large herds ( $\geq 150$ cows) had increased odds of being positive to Salmonella spp. and C. burnetii (Table 5) compared with the small herds ( $<50$ cows). The BVDV antigen and $O$. ostertagi could not be included in the multivariable analysis due to omitted observations in some of the categories of region or herd size.

\section{Repeated Quarterly Testing}

The quarterly testing for the presence of BVDV antigen and antibodies against MAP and F. hepatica in BMT samples was carried out between October 2014 and November 2015. The median interval between the second, third, and fourth quarterly test was 90, 92, and $89 \mathrm{~d}$, respectively, with a minimum of $19 \mathrm{~d}$ and a maximum of $190 \mathrm{~d}$ between any 2 tests carried out. The overall prevalence of BVDV and antibodies against MAP and F. hepatica in bulk milk, based on all 4 tests results, was estimated for 203, 206, and 206 farms, respectively. The results of prevalence at each quarterly testing as well as the overall (period) prevalence during the whole study period are presented in Figure 2. The true prevalence of BVDV antigen-positive herds was $5,11,11$, and $12 \%$ and of MAP antibody-positive farms was $68,72,83$, and $80 \%$ at each quarterly test, respectively. The apparent prevalence of $F$. hepatica antibody-positive herds at first, second, third, and fourth test was 55, 60, 57, and 56\%, respectively. During the whole study period, the true prevalence of herds testing positive at least once to BVDV antigen or antibodies against MAP was 19 (95\% CI: 13-26\%) and 89\% (95\% CI: $81-94 \%$ ), respectively; the apparent period prevalence of F. hepatica was $67 \%$ (95\% CI: $61-73 \%$ ).

\section{Farmers' Knowledge of Disease Status}

Approximately 19\% (42/224) of farms were members of 1 of the accredited herd health schemes, and $3 \%$ $(7 / 224)$ of farms were working toward membership at the time of the visit. Farmers' knowledge of the status of their herds with respect to the studied pathogens is summarized in Figure 3. Among unvaccinated herds, farmers believed MAP, F. hepatica, and BVDV to be present on 55, 46, and $30 \%$ of farms, respectively. Of the studied pathogens, the most frequently reported problems were due to MAP ( $41 \%$ of farms), whereas no problems due to Salmonella spp., $C$. burnetii, or $O$. 
VELASOVA ET AL.

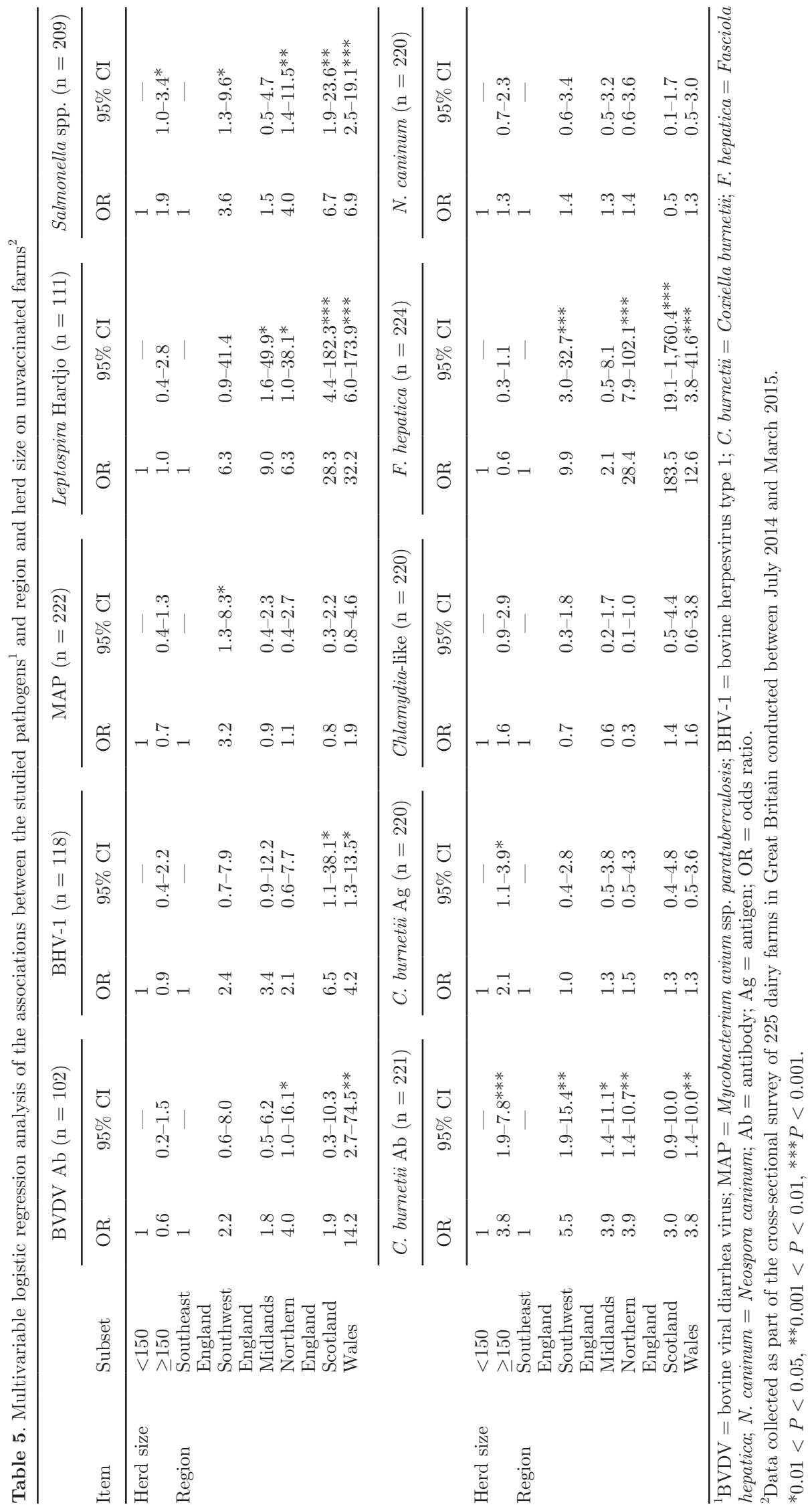




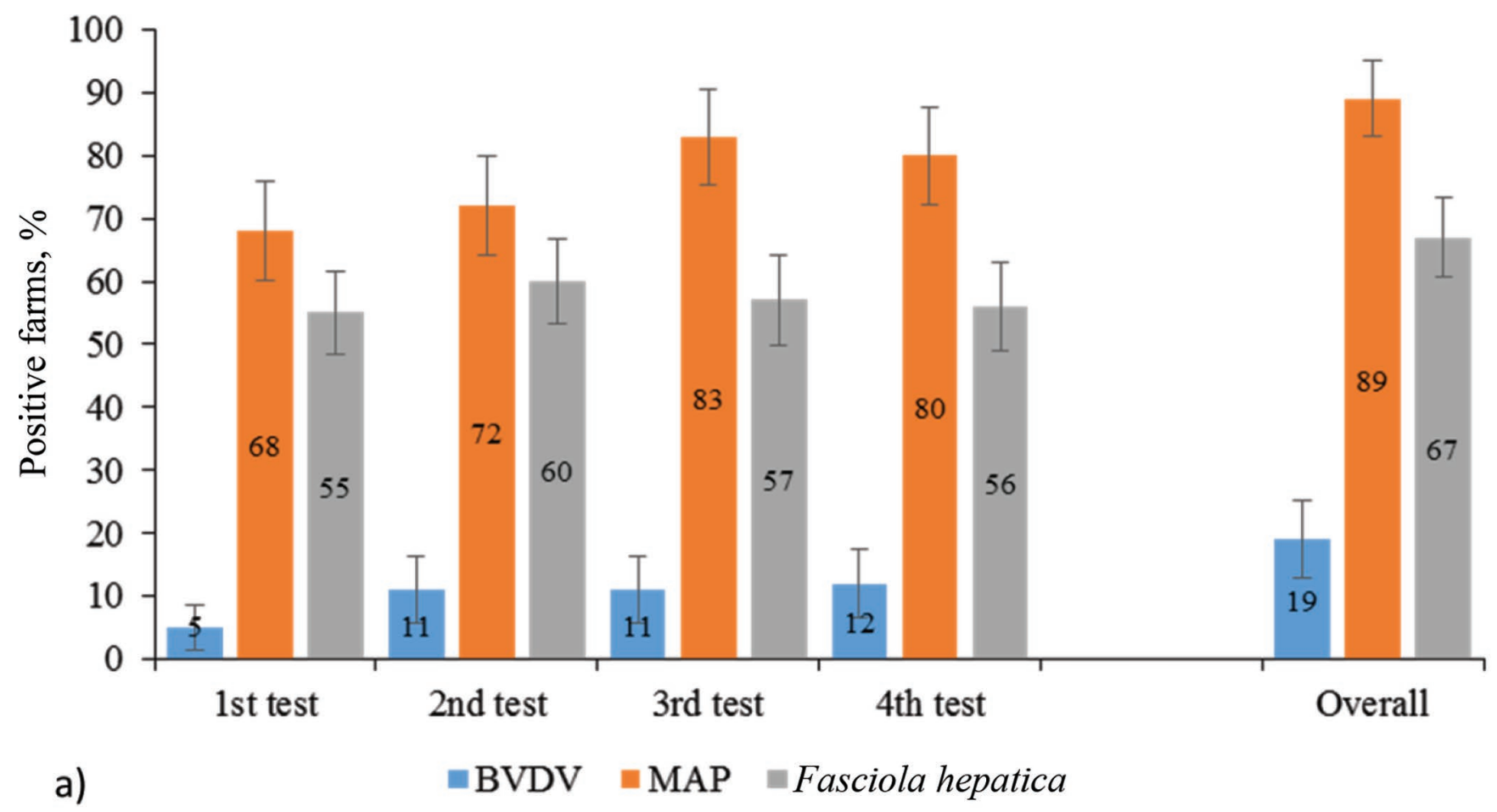

b)
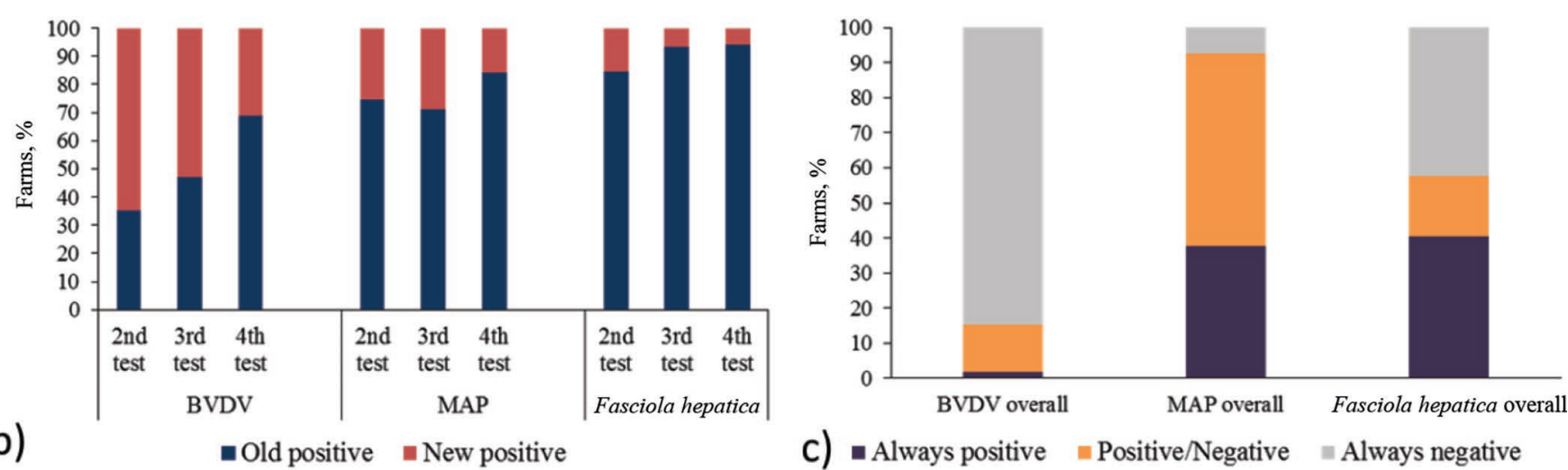

Figure 2. (a) The estimated point and overall (period) true prevalence of antibodies against Mycobacterium avium ssp. paratuberculosis (MAP) and bovine viral diarrhea virus (BVDV) antigen and 95\% CI of estimates tested using the bulk tank milk samples as part of the crosssectional study ( $\mathrm{n}=225$ dairy farms in Great Britain studied between July 2014 and November 2015). For Fasciola hepatica, the estimates and 95\% CI of apparent prevalence are presented. Dynamics of tested pathogens (b) expressed as proportion of old and new positive farms of the total number of positive farms detected at each quarterly test compared with the previous test result of a given pathogen; and (c) proportion of farms that tested always positive, changed between positive or negative, or always tested negative during the whole study period (July 2014 to November 2015). Color version available online.

ostertagi were reported (Figure 3). The percentage of herds where farmers correctly believed the disease in question was present that actually tested positive (positive predictive value) was high for C. burnetii $(100 \%$; although more than $50 \%$ of the farmers did not know the status), O. ostertagi (97\%), and BVDV antibody (92\%), but very low for BVDV antigen (5\%; Table 6). High negative predictive value of the farmers' perception was estimated for BVDV antigen (96\%).

\section{Spatial Distribution}

Accounting for the vaccination status, herds that tested positive for the individual pathogens were found in all studied regions. However, the variation in the distribution of the positive herds was marked across the regions (Figure $4 \mathrm{a}-\mathrm{c}$ ) with the lowest estimates found mostly in southeast England. Global spatial autocorrelation of positive unvaccinated herds was detected for 
Table 6. Farmers' perception ${ }^{1}$ of the disease status expressed as positive (PPV) and negative predictive values (NPV) using the bulk milk results as the gold standard

\begin{tabular}{llrrr}
\hline \multirow{2}{*}{$\begin{array}{l}\text { Pathogen } \\
\text { (antigen } \text { and type of test } \\
\text { in bulk milk sample) }\end{array}$} & & \multicolumn{2}{c}{$\begin{array}{c}\text { Farmers' perception } \\
\text { of current disease status }\end{array}$} \\
\cline { 2 - 5 } & Subset & $\mathrm{n}^{3}$ & PPV \% & NPV \% \\
\hline BVDV (antigen) & All farms & 202 & 5.0 & 95.9 \\
BVDV (antibody) & Unvaccinated & 92 & 92.3 & 53.0 \\
MAP (antibody) & Unvaccinated & 204 & 70.7 & 51.0 \\
Leptospira Hardjo (antibody) & Unvaccinated & 98 & 75.0 & 70.5 \\
Bovine herpes virus-1 (antibody) & Unvaccinated & 93 & 75.0 & 46.6 \\
Salmonella spp. (antibody) & Unvaccinated & 157 & 68.7 & 63.2 \\
Coxiella burnetii (antibody) & All farms & 75 & 100.0 & 31.5 \\
Coxiella burnetii (antigen) & All farms & 75 & 100.0 & 80.8 \\
Fasciola hepatica (antibody) & All farms & 192 & 64.9 & 73.5 \\
Neospora caninum (antibody) & All farms & 165 & 61.3 & 63.1 \\
Ostertagia ostertagi (antibody) & All farms & 166 & 97.2 & 7.5 \\
\hline
\end{tabular}

${ }^{1}$ The perception was recorded at the time of the visit before the single laboratory testing of the bulk milk samples carried out as part of the cross-sectional study of 225 dairy farms in Great Britain carried out between July 2014 and March 2015.

${ }^{2} \mathrm{BVDV}=$ bovine viral diarrhea virus; MAP $=$ Mycobacterium avium ssp. paratuberculosis.

${ }^{3} \mathrm{n}=$ number of farms. Farms on which the disease status was unknown were excluded from the calculation of the PPV and NPV.

BVDV antibodies $(I=0.23, P=0.02), F$. hepatica $(I$ $=0.22, P=0.008)$, and Salmonella spp. $(I=0.18, P$ $=0.02)$. Spatial autocorrelation of $C$. burnetii PCRpositive herds was also detected $(I=0.03, P=0.02)$. By means of the scan statistic, both low- and high-risk clusters of positive unvaccinated herds were found for F. hepatica, Leptospira Hardjo, Salmonella spp., and for BVDV antibodies. Further, 1 high-risk cluster for BVDV antigen and $O$. ostertagi and 1 low-risk cluster for C. burnetii antibody-positive herds were found

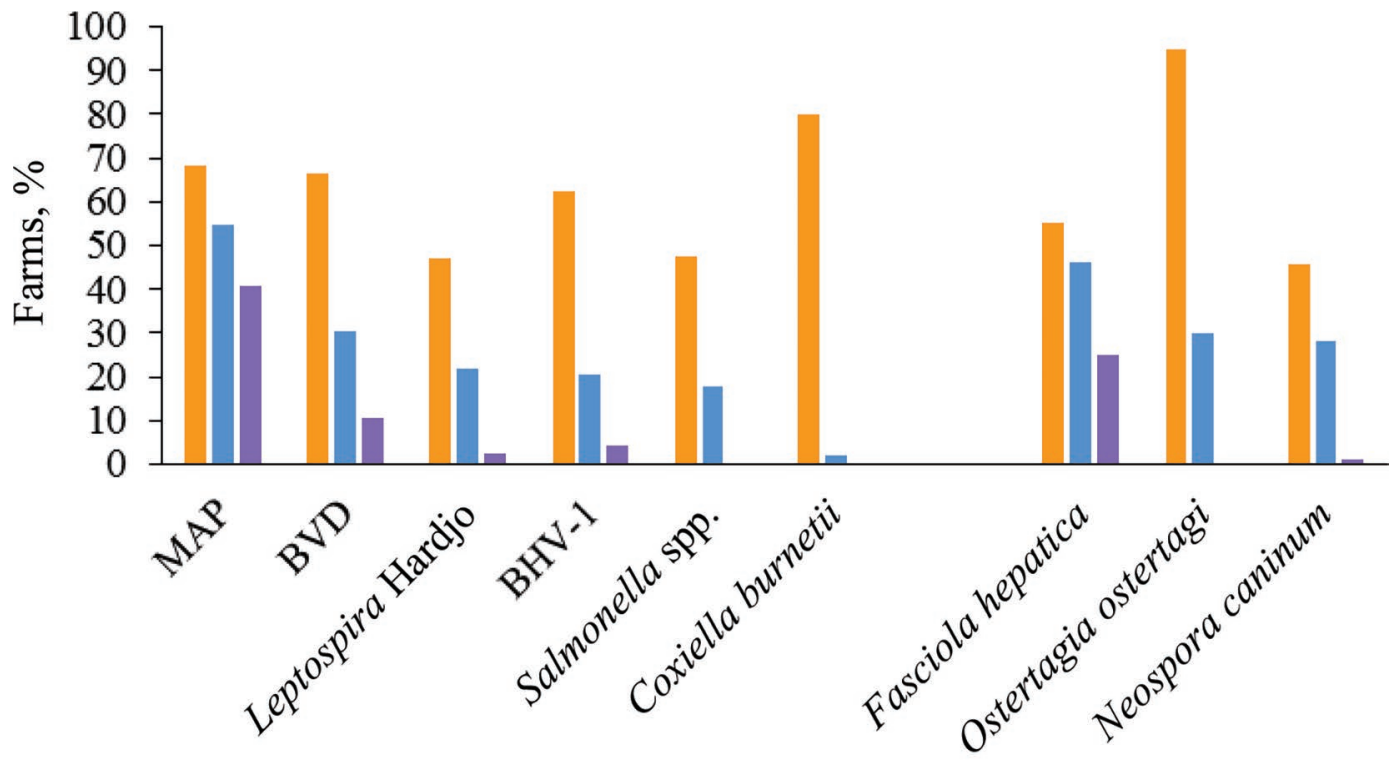

$\square$ Antibody test positive $\quad$ Believed as present $\quad$ Believed as problem

Figure 3. Farmers' perception of the herd disease status at the time of the visit before the laboratory testing of bulk milk samples being carried out accounted for the vaccination status. "Believed as present" represents farms where farmers knew the disease was present based on the results of previous test or based on their perception. "Believed as problem" represents farms where farmers believed that the listed disease was a problem at the time of the visit. "Antibody test positive" represents the true proportion of positive unvaccinated farms based on the detection of antibodies against tested pathogens using single bulk tank milk samples collected between July 2014 and March 2015 (n = 225 dairy farms in Great Britain). BVD = bovine viral diarrhea virus; MAP = Mycobacterium avium ssp. paratuberculosis; BHV-1 = bovine herpes virus 1 . Color version available online. 
(Figure 5 a,b). All low-risk clusters were located in southeast England.

\section{DISCUSSION}

To inform decisions regarding disease priorities and suitable control programs and to allow for monitoring of disease trends over time, reliable and up-to-date information on disease prevalence is highly desirable. With this in mind, the present study was designed to provide prevalence estimates representative of the national GB dairy herd for several nonstatutory infectious diseases assumed endemic. Bovine tuberculosis, although identified as important during the workshop, was not included in the study due to the fact that existing mandatory surveillance provides reliable information on its occurrence at the national level (Velasova et al., 2015). Participation in the study was voluntary; however, when compared nationally, although the estimated weighted average herd size of 187 cows was slightly higher than that of 144 cows for the GB dairy herd, the estimated average annual milk yield was comparable with the national estimate of 7,535 L (DairyCo, 2013). This suggests that the data were not noticeably biased in this respect. The use of stratified sampling by region and herd size further allowed us to produce national prevalence estimates with smaller standard errors compared with a nonstratified study of the same size.

The results of high prevalence and wide geographic distribution confirm that the studied pathogens are spread widely across GB and that, at the time of the study, a large proportion of the dairy herds in GB had previously been exposed to them. The high prevalence levels further suggest that active disease transmission is occurring among the dairy cattle population and that available control measures are either not being implemented or not being effective. The estimated prevalence values of most of the studied pathogens broadly agree with those reported from other countries, where these pathogens are considered endemic, suggesting similar pathogen dynamics [BVDV and BHV-1 (Kampa et al., 2004; Sayers et al., 2015; Fernandes et al., 2016), MAP (Muskens et al., 2000; van Schaik et al., 2003), C. burnetii (van Engelen et al., 2014), Salmonella spp., and Leptospira Hardjo (Habing et al., 2012; O'Doherty et al., 2013). Higher-prevalence estimates of F. hepatica (Cringoli et al., 2002; Olsen et al., 2015) and N. caninum infections were estimated in our study compared with some other countries (Sanderson et al., 2000; O'Doherty et al., 2013).

Bulk milk samples were used to assess herd status based on the presence of specific antibodies or antigen. Our prevalence estimates are therefore herd-level esti- mates and they are subject to misclassification bias as a result of imperfect Se or Sp of the tests applied at the level of the herd. Ascertainment of the infection status of a herd by means of testing a single milk sample from the bulk tank is well established and has obvious logistical and financial advantages. On the other hand, the use of bulk milk comes with limitations, as the ability to identify infected herds (sensitivity) is compromised, in particular for pathogens that can be present in the herd at low levels. In this situation, negative results should be interpreted as a herd with less than a minimum proportion of positive animals among those in milk needed for the expected ability of the diagnostic test to classify herd as positive. When possible, we tried to adjust the apparent prevalence obtained for the imperfect performance of the test using available values of herd-level Se and Sp. This information was, however, not available for some of the studied pathogens, such as C. burnetii, F. hepatica, N. caninum, and O. ostertagi. As a result, only estimates of their apparent prevalence are presented. In addition, we assumed all PCR tests to have $100 \%$ Se and Sp, which could have resulted in the misclassification bias. Another limitation is that the antibodies detected in BMT sample may be indicative of historical rather than active or recent infection (Lindberg and Alenius, 1999; Booth et al., 2013; Sayers et al., 2015), and that the bulk milk sample does not include the whole herd. Young stock, clinically ill cows, and dry cows were excluded from the sample. As a result, for example, the prevalence of BVDV antigen in bulk milk can be underestimated due to premature culling of infected young stock (Bishop et al., 2010). Similarly, the prevalence of MAP can be underestimated due to the susceptibility of cows infected with MAP to secondary conditions (e.g., mastitis or lameness; Villarino and Jordan, 2005) and the subsequent exclusion of cows treated with antibiotics from milk sampling and testing. Furthermore, exclusion of the vaccinated herds from the study population resulted in lower precision of the prevalence estimates, such that the smallest number of the studied unvaccinated herds (102 herds) was sufficient to estimate $50 \%$ prevalence (the worst-case scenario) with $10 \%$ precision and $95 \%$ confidence.

Regional variations in prevalence of some of the studied pathogens have been reported previously (Ryan et al., 2012; Howell et al., 2015; Sayers et al., 2015). Overall, we found a lower proportion of positive herds in southeast England, where cattle density is lower $(<10$ dairy cows per 100 ha of farmed land) compared with the other studied regions (CHAWG, 2012). Other factors, such as herd size, management practices (biosecurity, purchase of new stock), and environmental conditions (i.e., temperature, type of land), can be used to explain the observed regional differences in the 

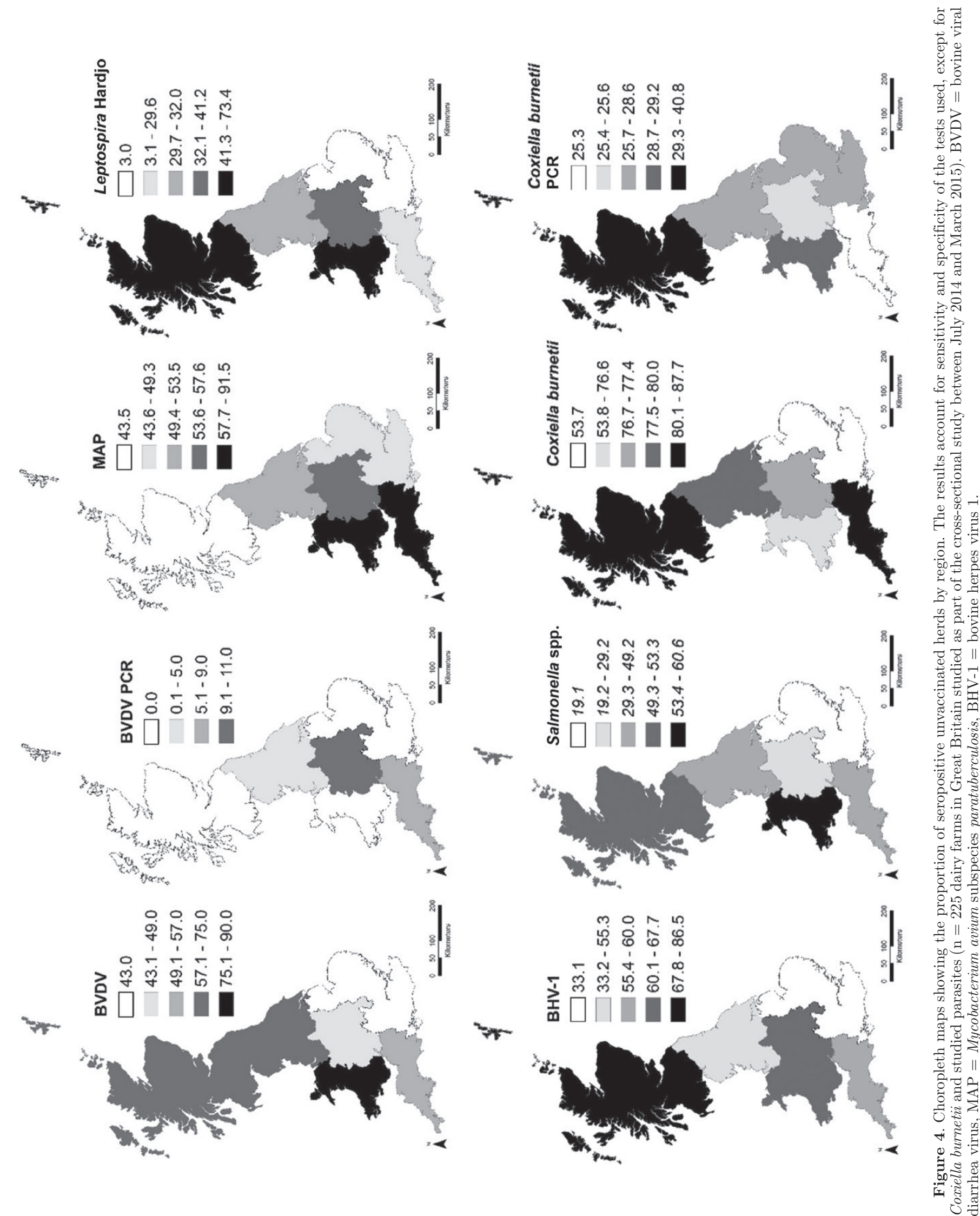

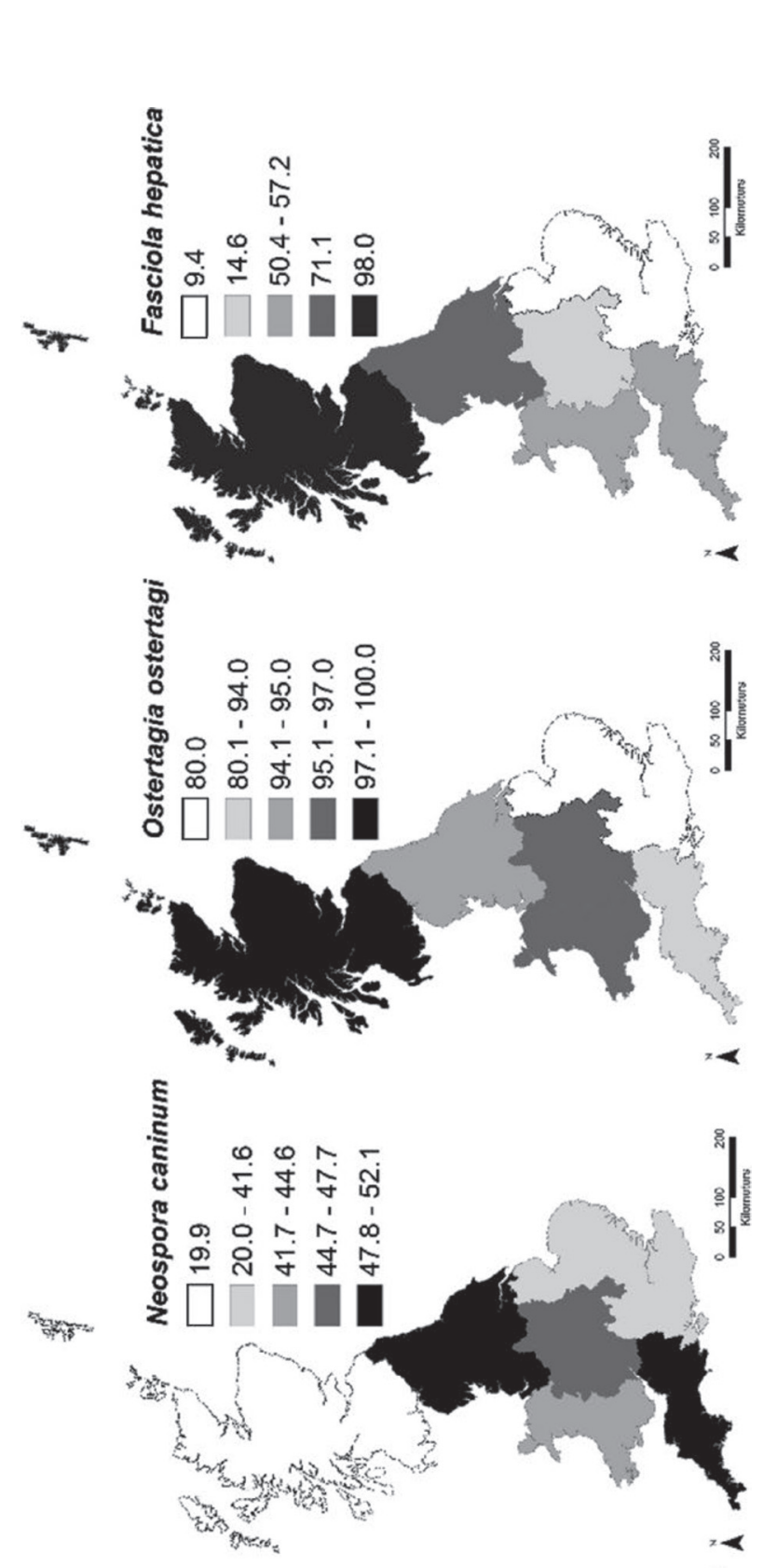

罂

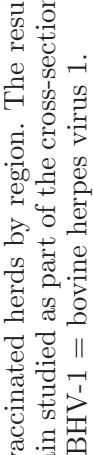

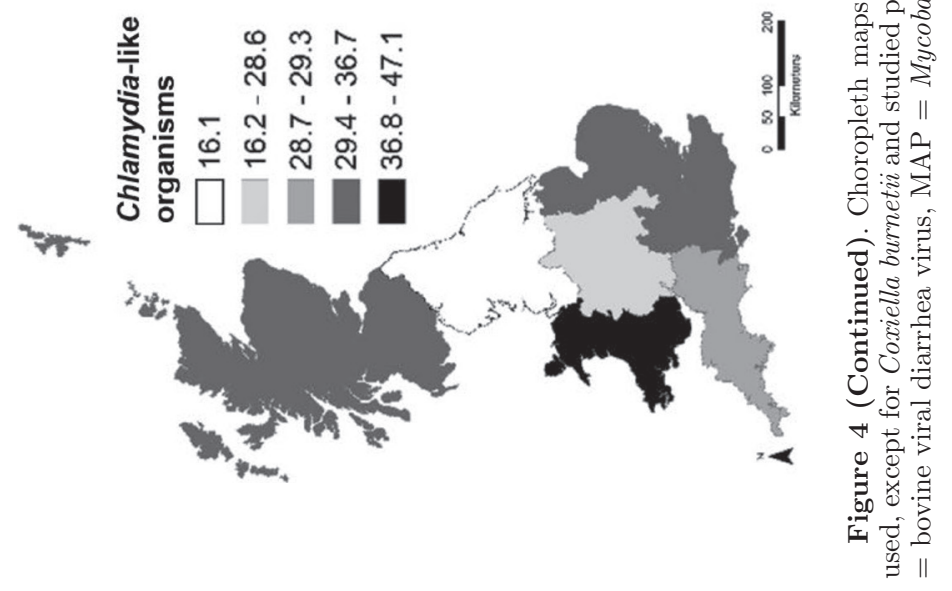




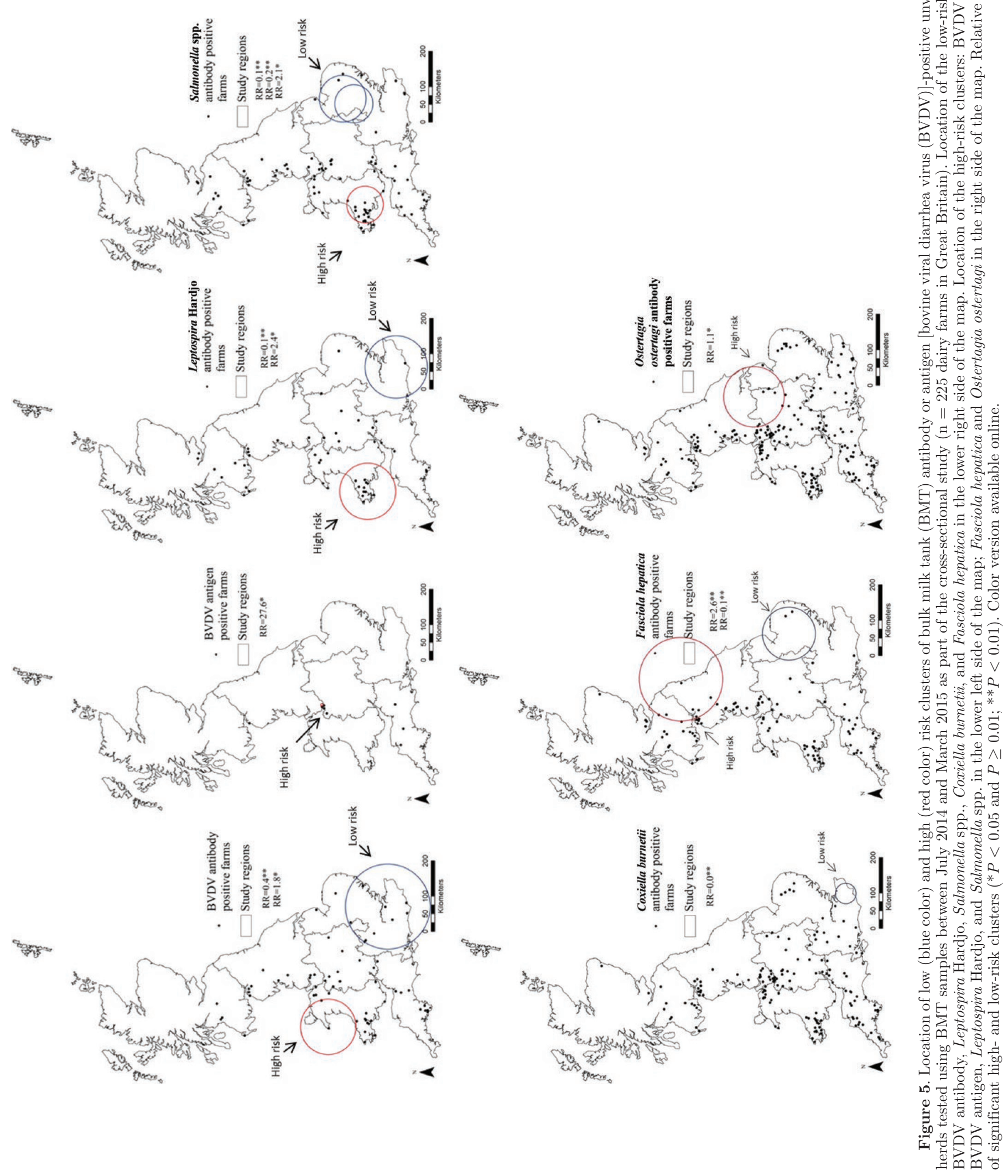


number of positive herds. However, comparison at regional level has to be done with caution, as the present national study was not designed to generate prevalence estimates at regional level.

A relatively high number of studied farms were vaccinated against $\mathrm{BVDV}, \mathrm{BHV}-1$, and Leptospira Hardjo, which indicates farmers' understanding of a need for disease control measures. Only the results of unvaccinated herds are presented, as the diagnostic tests used in our study were unable to differentiate between vaccinated and infected herds. The presence of a correlation between the positive status for BVDV antibodies, BHV-1, Leptospira Hardjo, MAP, and F. hepatica suggests similar risk factors for infections due to these pathogens, which is in agreement with the previous reports (Paton et al., 1998; Kampa et al., 2004; Williams and Winden, 2014). The high level of antibodies against BVDV and BHV-1 detected in several herds is suggestive of the presence of active infection or in case of BVDV, also presence or recent removal of persistently infected animal(s) (Kampa et al., 2004; Booth et al., 2013). However, the detection of a low positive correlation between BVDV antibody and antigen positive herds in our study is indicative of detection of historical infections on several farms, as the antibodies can persist in bulk milk up to 3 to 4 yr in previously infected herds (Lindberg and Alenius, 1999). The observed variation in the level of BHV1 BMT antibody detected agrees with the previous report of herds being either strongly positive or with very low or no antibody detected (Paton et al., 1998). Furthermore, the estimated prevalence of BHV-1 is almost identical to the values reported from previous surveys, indicating the stability of the virus in the population of GB dairy herds (Paton et al., 1998; Williams and Winden, 2014).

The high apparent prevalence of BMT antibodies against $O$. ostertagi, $F$. hepatica, and $N$. caninum is not surprising. It has been reported that $O$. ostertagi is present in all herds and that the majority of type 1 ostertagiosis infections occur during summer months (Sekiya et al., 2013). Higher proportions of O. ostertagi and F. hepatica BMT antibody-positive herds were found in the northern parts of GB. This is most likely due to the effect of environmental factors (i.e., higher rainfall in these regions in 2014; MetOffice, 2014) as well as differences in grazing practices (i.e., access to pasture and duration of grazing; Sekiya et al., 2013). In relation to $N$. caninum, seasonal variation in the prevalence has been previously reported (O'Doherty et al., 2013). Due to limited financial resources in our study, only a single testing was carried out, which could have resulted in some positive herds being missed, especially on farms tested during early stages of the lactation
(O'Doherty et al., 2013). However, in our study the majority of the herds (74\%) were calving year round. Furthermore, the first testing was carried out between July 2014 and March 2015, with the majority (64\%) of the samples tested between July and September 2014 minimizing the number of false-negative results on farms with seasonal calving.

The prevalence of Salmonella spp. and C. burnetii in a population of dairy herds in GB was high. However, no farmer reported problems due to these pathogens, indicating that they are mostly subclinical or unrecognized. It further suggests that the importance of a pathogen or disease and willingness to act on depend not just on prevalence but also on attributable economic effects. As a result, without routine screening, infected herds will remain undetected and pose a risk for disease transmission, especially in areas with high cattle density. The differences in environmental and climatic conditions (i.e., type of landscape, cattle density, temperature, rainfall, wind) were also reported to play an important role in relation to the regional variations we observed for these pathogens (Davison et al., 2005; Nusinovici et al., 2015). Similarly, diverse ecological niches and a wide hosts range for Chlamydialike organisms have been reported (Taylor-Brown et al., 2015). In addition to their presence in environment, previous studies in GB have also observed the evidence of Chlamydia-like organisms in $18 \%$ of bovine placenta samples in Scotland (Wheelhouse et al., 2012) and in approximately $10 \%$ of bovine samples in England and Wales (Wheelhouse et al., 2015).

The repeated testing for BVDV antigen and antibodies against MAP and F. hepatica allowed us to observe trends in antibody levels. The exposure of herds to $F$. hepatica appeared to be stable during the whole followup period, suggesting the endemicity of the infection on the farms. In relation to MAP infections, changes from positive to negative or negative to positive status were observed in more than half of the herds during the follow up period. The changes could be due to the low sensitivity of the MAP ELISA (van Weering et al., 2007), purchase of seropositive animals on open farms, or exclusion of dry or seropositive animals from the BMT testing. Changes in BVDV antigen status during the study period could also be due to a purchase or removal of infected animals from the herd or bulk milk sample at the time of the testing or due to a persistently infected heifer entering the milking herd (Booth and Brownlie, 2012). The observed changes in prevalence of BVDV antigen and antibodies against MAP, together with the results of farmers' perception of disease status, highlight the importance and value of repeated testing in correctly identifying infected herds and, hence, appropriate control measures. 
Given the importance of accurate and reliable baseline data for the effective implementation and monitoring of disease control programs, the results of our study are particularly valuable. That is because the results of our study not only provide much-needed baseline data for the control of endemic pathogens (for which monitoring is already underway in GB; i.e., BVDV), but also for other pathogens that are not presently being monitored at the national level in GB.

\section{CONCLUSIONS}

Dairy herds in GB are frequently exposed to several endemic pathogens that are prevalent at high levels and exhibit some geographical variations. Given the burden to efficient production that those pathogens pose, and in some cases their public health implications, the implementation of measures to control and possibly eliminate some of these pathogens should be given consideration. Despite some limitations, the prevalence figures estimated in this study provide a basis for the future monitoring of disease trends over time and can be used to assess the effectiveness of future disease control programs implemented at the national level.

\section{ACKNOWLEDGMENTS}

We are grateful to all the farmers who participated in the study and all the veterinarians who helped with the farm recruitment. Without their help, this project would not be possible. We thank the National Milk Laboratories (Wolverhampton, UK) and Moredun Research Institute for testing the samples. This project was funded by AHDB Dairy, a division of the Agriculture and Horticulture Development Board, with a contribution from grant BB/J015601/1 funded by the Biotechnology and Biological Sciences Research Council (BBSRC, Swindon, UK) and Zoetis (Kalamazoo, MI).

\section{REFERENCES}

Ackermann, M., and M. Engels. 2006. Pro and contra IBR-eradication. Vet. Microbiol. 113:293-302.

Anselin, L. 2004. Exploring spatial data with GeoDa: A workbook. CSISS, Santa Barbara, CA.

Anselin, L., W. Y. Kim, and I. Syabri. 2004. Web-based analytical tools for the exploration of spatial data. J. Geogr. Syst. 6:197-218.

Barkema, H. W., M. A. G. von Keyserlingk, J. P. Kastelic, T. J. G. M. Lam, C. Luby, J. P. Roy, S. J. LeBlanc, G. P. Keefe, and D. F. Kelton. 2015. Invited review: Changes in the dairy industry affecting dairy cattle health and welfare. J. Dairy Sci. 98:7426-7445.

Bennett, R., and J. Ijpelaar. 2005. Updated estimates of the costs associated with thirty-four endemic livestock diseases in Great Britain: A note. J. Agric. Econ. 56:135-144.

Bishop, H., J. Erkelens, and S. Van Winden. 2010. Indications of a relationship between buying-in policy and infectious diseases on dairy farms in Wales. Vet. Rec. 167:644-647.
Booth, R. E., and J. Brownlie. 2012. Establishing a pilot bovine viral diarrhoea virus eradication scheme in Somerset. Vet. Rec. 170:73.

Booth, R. E., M. P. Cranwell, and J. Brownlie. 2013. Monitoring the bulk milk antibody response to BVD: The effects of vaccination and herd infection status. Vet. Rec. 172:449.

Carslake, D., W. Grant, L. E. Green, J. Cave, J. Greaves, M. Keeling, J. McEldowney, H. Weldegebriel, and G. F. Medley. 2011. Endemic cattle diseases: comparative epidemiology and governance. Phil. Trans. R. Soc. Lond. B Biol. Sci. 366:1975-1986.

CHAWG. 2012. First Annual Report-GB Cattle Health and Welfare Group. Accessed Dec. 12, 2016. http://beefandlamb.ahdb.org .uk/wp/wp-content/uploads/2013/06/Cattle-Health-and-Welfare -Report.pdf.

Cringoli, G., L. Rinaldi, V. Veneziano, G. Capelli, and J. B. Malone. 2002. A cross-sectional coprological survey of liver flukes in cattle and sheep from an area of the southern Italian Apennines. Vet. Parasitol. 108:137-143.

DairyCo. 2013. Dairy statistics: An insider's guide 2013. Vol. 2013, Kenilworth. Accessed Feb. 12, 2017. https://dairy.ahdb.org .uk/resources-library/market-information/dairy-statistics/dairy -statistics-an-insiders-guide-2013/\#.WKMnKphDTIU.

Davison, H. C., R. P. Smith, S. J. Pascoe, A. R. Sayers, R. H. Davies, J. P. Weaver, S. A. Kidd, R. W. Dalziel, and S. J. Evans. 2005. Prevalence, incidence and geographical distribution of serovars of Salmonella on dairy farms in England and Wales. Vet. Rec. 157:703-711.

Fernandes, L. G., A. H. de Campos Nogueira, E. De Stefano, E. M. Pituco, C. P. Ribeiro, C. J. Alves, T. S. Oliveira, I. J. Clementino, and S. S. de Azevedo. 2016. Herd-level prevalence and risk factors for bovine viral diarrhea virus infection in cattle in the State of Paraíba, Northeastern Brazil. Trop. Anim. Health Prod. 48:157-165.

Fray, M. D., G. E. Mann, M. C. Clarke, and B. Charleston. 2000. Bovine viral diarrhoea virus: its effects on ovarian function in the cow. Vet. Microbiol. 77:185-194.

Frössling, J., A. Lindberg, and C. Bjorkman. 2006. Evaluation of an iscom ELISA used for detection of antibodies to Neospora caninum in bulk milk. Prev. Vet. Med. 74:120-129.

Habing, G. G., J. E. Lombard, C. A. Kopral, D. A. Dargatz, and J. B. Kaneene. 2012. Farm-level associations with the shedding of Salmonella and antimicrobial-resistant Salmonella in U.S. dairy cattle. Foodborne Pathog. Dis. 9:815-821.

Houe, H., A. Lindberg, and V. Moennig. 2006. Test strategies in bovine viral diarrhea virus control and eradication campaigns in Europe. J. Vet. Diagn. Invest. 18:427-436.

Howell, A., M. Baylis, R. Smith, G. Pinchbeck, and D. Williams. 2015. Epidemiology and impact of Fasciola hepatica exposure in highyielding dairy herds. Prev. Vet. Med. 121:41-48.

Humphry, R. W., F. Brulisauer, I. J. McKendrick, P. F. Nettleton, and G. J. Gunn. 2012. Prevalence of antibodies to bovine viral diarrhoea virus in bulk tank milk and associated risk factors in Scottish dairy herds. Vet. Rec. 171:445.

Kampa, J., K. Ståhl, J. Moreno-López, A. Chanlun, S. Aiumlamai, and S. Alenius. 2004. BVDV and BHV-1 infections in dairy herds in northern and northeastern Thailand. Acta Vet. Scand. 45:181-192.

Klee, S. R., J. Tyczka, H. Ellerbrok, T. Franz, S. Linke, G. Baljer, and B. Appel. 2006. Highly sensitive real-time PCR for specific detection and quantification of Coxiella burnetii. BMC Microbiol. 6:2.

Kulldorff, M. 1997. A spatial scan statistic. Commun. Stat. Theory Methods 26:1481-1496.

Lanyon, S. R., F. I. Hill, M. P. Reichel, and J. Brownlie. 2014. Bovine viral diarrhoea: Pathogenesis and diagnosis. Vet. J. 199:201-209.

Lienard, J., A. Croxatto, S. Aeby, K. Jaton, K. Posfay-Barbe, A. Gervaix, and G. Greub. 2011. Development of a new chlamydialesspecific real-time PCR and its application to respiratory clinical samples. J. Clin. Microbiol. 49:2637-2642.

Lindberg, A., J. Brownlie, G. J. Gunn, H. Houe, V. Moennig, H. W. Saatkamp, T. Sandvik, and P. S. Valle. 2006. The control of bovine viral diarrhoea virus in Europe: Today and in the future. Rev. Sci. Tech. 25:961-979. 
Lindberg, A. L., and S. Alenius. 1999. Principles for eradication of bovine viral diarrhoea virus (BVDV) infections in cattle populations. Vet. Microbiol. 64:197-222.

McAloon, C. G., P. Whyte, S. J. More, M. J. Green, L. O'Grady, A. Garcia, and M. L. Doherty. 2016. The effect of paratuberculosis on milk yield - A systematic review and meta-analysis. J. Dairy Sci. 99:1449-1460.

Met Office. 2014. Regional values-Annual 2014. Accessed Dec. 10, 2016. http://www.metoffice.gov.uk/climate/uk/summaries/2014/ annual/regional-values.

Murphy, T. M., K. N. Fahy, A. McAuliffe, A. B. Forbes, T. A. Clegg, and D. J. O'Brien. 2006. A study of helminth parasites in culled cows from Ireland. Prev. Vet. Med. 76:1-10.

Muskens, J., H. W. Barkema, E. Russchen, K. van Maanen, Y. H. Schukken, and D. Bakker. 2000. Prevalence and regional distribution of paratuberculosis in dairy herds in the Netherlands. Vet. Microbiol. 77:253-261.

Nusinovici, S., J. Frossling, S. Widgren, F. Beaudeau, and A. Lindberg. 2015. Q fever infection in dairy cattle herds: Increased risk with high wind speed and low precipitation. Epidemiol. Infect. 143:3316-3326.

Nyman, A. K., E. C. Agren, K. Bergstrom, and H. Wahlstrom. 2013 Evaluation of the specificity of three enzyme-linked immunosorbent assays for detection of antibodies against Salmonella in bovine bulk milk. Acta Vet. Scand. 55:5.

O'Doherty, E., RSayers, and L. O'Grady. 2013. Temporal trends in bulk milk antibodies to Salmonella, Neospora caninum, and Leptospira interrogans serovar hardjo in Irish dairy herds. Prev. Vet. Med. 109:343-348.

Olivier, J., and M. L. Bell. 2013. Effect sizes for $2 \times 2$ contingency tables. PLoS One 8:e58777.

Olsen, A., K. Frankena, R. Bødker, N. Toft, S. M. Thamsborg, H. L. Enemark, and T. Halasa. 2015. Prevalence, risk factors and spatial analysis of liver fluke infections in Danish cattle herds. Parasit. Vectors 8:160.

Paton, D. J., K. H. Christiansen, S. Alenius, M. P. Cranwell, G. C. Pritchard, and T. W. Drew. 1998. Prevalence of antibodies to bovine virus diarrhoea virus and other viruses in bulk tank milk in England and Wales. Vet. Rec. 142:385-391.

Reichel, M. P., K. Vanhoff, and B. Baxter. 2005. Performance characteristics of an enzyme-linked immunosorbent assay performed in milk for the detection of liver fluke (Fasciola hepatica) infection in cattle. Vet. Parasitol. 129:61-66.

Rogan, W. J., and B. Gladen. 1978. Estimating prevalence from the results of a screening test. Am. J. Epidemiol. 107:71-76.

Ryan, E. D., M. Kirby, D. M. Collins, R. Sayers, J. F. Mee, and T. Clegg. 2011. Prevalence of Coxiella burnetii (Q fever) antibodies in bovine serum and bulk-milk samples. Epidemiol. Infect. 139:14131417.

Ryan, E. G., N. Leonard, L. O'Grady, S. J. More, and M. L. Doherty. 2012. Seroprevalence of Leptospira Hardjo in the Irish suckler cattle population. Ir. Vet. J. 65:8.

Salimi-Bejestani, M. R., R. G. Daniel, S. M. Felstead, P. J. Cripps, H. Mahmoody, and D. J. Williams. 2005. Prevalence of Fasciola hepatica in dairy herds in England and Wales measured with an ELISA applied to bulk-tank milk. Vet. Rec. 156:729-731.

Sanderson, M. W., J. M. Gay, and T. V. Baszler. 2000. Neospora caninum seroprevalence and associated risk factors in beef cattle in the northwestern United States. Vet. Parasitol. 90:15-24.

Sayers, R. G., N. Byrne, E. O'Doherty, and S. Arkins. 2015. Prevalence of exposure to bovine viral diarrhoea virus (BVDV) and bovine herpesvirus-1 (BoHV-1) in Irish dairy herds. Res. Vet. Sci. 100:21-30.

Sekiya, M., A. Zintl, and M. L. Doherty. 2013. Bulk milk ELISA and the diagnosis of parasite infections in dairy herds: a review. Ir. Vet. J. 66:14.
Smith, R. L., R. L. Strawderman, Y. H. Schukken, S. J. Wells, A. K. Pradhan, L. A. Espejo, R. H. Whitlock, J. S. Van Kessel, J. M. Smith, D. R. Wolfgang, and Y. T. Grohn. 2010. Effect of Johne's disease status on reproduction and culling in dairy cattle. J. Dairy Sci. 93:3513-3524.

StataCorp. 2013. Stata: Release 13. Statistical Software. StataCorp LP, Stata Press, College Station, TX. Accessed May 10, 2017. http://www.stata.com/manuals13/svy.pdf.

Statham, J. 2011. Cattle health schemes. In Pract. 33:210-217.

Stott, A. W., G. M. Jones, R. W. Humphry, and G. J. Gunn. 2005. Financial incentive to control paratuberculosis (Johne's disease) on dairy farms in the United Kingdom. Vet. Rec. 156:825-831.

Taylor-Brown, A., L. Vaughan, G. Greub, P. Timms, and A. Polkinghorne. 2015. Twenty years of research into Chlamydia-like organisms: A revolution in our understanding of the biology and pathogenicity of members of the phylum Chlamydiae. Pathog. Dis. $73: 1-15$.

Tiwari, A., J. A. Vanleeuwen, I. R. Dohoo, G. P. Keefe, J. P. Haddad, R. Tremblay, H. M. Scott, and T. Whiting. 2007. Production effects of pathogens causing bovine leukosis, bovine viral diarrhea, paratuberculosis, and neosporosis. J. Dairy Sci. 90:659-669.

van Engelen, E., N. Schotten, B. Schimmer, J. L. Hautvast, G. van Schaik, and Y. T. van Duijnhoven. 2014. Prevalence and risk factors for Coxiella burnetii (Q fever) in Dutch dairy cattle herds based on bulk tank milk testing. Prev. Vet. Med. 117:103-109.

van Schaik, G., Y. H. Schukken, C. Crainiceanu, J. Muskens, and J. A. VanLeeuwen. 2003. Prevalence estimates for paratuberculosis adjusted for test variability using Bayesian analysis. Prev. Vet. Med. 60:281-295.

van Weering, H., G. van Schaik, A. van der Meulen, M. Waal, P. Franken, and K. van Maanen. 2007. Diagnostic performance of the Pourquier ELISA for detection of antibodies against Mycobacterium avium subspecies paratuberculosis in individual milk and bulk milk samples of dairy herds. Vet. Microbiol. 125:49-58.

Velasova, M., J. A. Drewe, J. Gibbons, M. Green, and J. Guitian. 2015. Evaluation of the usefulness at national level of the dairy cattle health and production recording systems in Great Britain. Vet. Rec. 177:304.

Villarino, M. A., and E. R. Jordan. 2005. Production impact of subclinical manifestations of bovine paratuberculosis in dairy cattle. in Proc. 8th Int. Colloquium on Paratuberculosis. Copenhagen, Denmark, August 14-17, 2005.

Walz, P. H., T. Montgomery, T. Passler, K. P. Riddell, T. D. Braden, Y. Zhang, P. K. Galik, and S. Zuidhof. 2015. Comparison of reproductive performance of primiparous dairy cattle following revaccination with either modified-live or killed multivalent viral vaccines in early lactation. J. Dairy Sci. 98:8753-8763.

Wheelhouse, N., F. Howie, J. Gidlow, G. Greub, M. Dagleish, and D. Longbottom. 2012. Involvement of Parachlamydia in bovine abortions in Scotland. Vet. J. 193:586-588.

Wheelhouse, N., R. Mearns, K. Willoughby, E. Wright, D. Turnbull, and D. Longbottom. 2015. Evidence of members of the Chlamydiales in bovine abortions in England and Wales. Vet. Rec. 176:465.

Williams, D., and S. V. Winden. 2014. Risk factors associated with high bulk milk antibody levels to common pathogens in UK dairies. Vet. Rec. 174:580.

Woodbine, K. A., G. F. Medley, S. J. Moore, A. M. Ramirez-Villaescusa, S. Mason, and L. E. Green. 2009a. A four year longitudinal sero-epidemiological study of bovine herpesvirus type-1 (BHV-1) in adult cattle in 107 unvaccinated herds in south west England. BMC Vet. Res. 5:5.

Woodbine, K. A., Y. H. Schukken, L. E. Green, A. Ramirez-Villaescusa, S. Mason, S. J. Moore, C. Bilbao, N. Swann, and G. F. Medley. 2009b. Seroprevalence and epidemiological characteristics of Mycobacterium avium ssp. paratuberculosis on 114 cattle farms in south west England. Prev. Vet. Med. 89:102-109. 